\title{
Herbal untuk Perawatan Masa Nifas; Penggunaan Kayu Manis untuk Nyeri Perineum dan Luka Episiotomi
}

\author{
Eka Tri Wulandari ${ }^{1}$, Desi Kumalasari ${ }^{2}$ \\ Program Studi Kebidanan, STIKes AISYAH Pringsewu Lampung ${ }^{1,2}$ \\ Jl.A.Yani No IA Tambahrejo Kecamatan Gadingrejo Kabupaten Pringsewu Lampung \\ 35372 Indonesia Telp.0729333343 \\ Email:fatihnyaumi@gmail.com ${ }^{1}$, kumalasaridesi70@gmail.com²
}

\begin{abstract}
ABSTRAK
Episiotomi merupakan tindakan Obtetrik yang umum dilakukan pada proses persalinan di dunia. Prevalensi episiotomi pada ibu primipara dilaporkan sebesar 43\% sampai $100 \%$, bahkan di Iran dilaporkan hampir 100\% rumah melakukan tindakan episiotomi. Rasa sakit pada bekas episiotomi dapat mempengaruhi kondisi ibu pada masa nifas, antara lain saat laktasi, perawatan bayinya, dan aktivitas kesehariannya. Ada beberapa metode yang bisa dipakai untuk mengurangi rasa sakit dan mempercepat penyembuhan luka episiotomi, salah satunya dengan pengobatan herbal, yaitu dengan kayumanis. Kayumanis mempunyai efek anti inflamasi dan analgesik. Senyawa aktif yang terkandung dalam kayumanis antara lain cinnamaldehyde, eugenol, cinnzeylanine, cinzeylanol,arabinoxylan, 2-hydroxycinnamaldehide, dan 2-benzoloxycinnamaldehyde. Pada penelitian eksperimen yang bertujuan untuk mengetahui efek kayumanis terhadap nyeri dan luka episiotomi dengan jumlah responden 114 ibu pospartum, menunjukan bahwa Kayu manis dapat digunakan untuk mengurangi nyeri perineum dan mempercepat proses kesembuhan dari luka episiotomi.
\end{abstract}

Kata kunci : episiotomi, kayumanis, nyeri perineum

\section{HERB FOR POSTPARTUM TREATMENT; THE USE OF CINNAMON FOR PERINEAL PAIN AND EPISIOTOMY WOUND}

\begin{abstract}
Episiotomy is the most common obstetric intervention in the word. Its prevalence has been reported to be $43 \%$ to $100 \%$ in primiparous women in Asia and up to $100 \%$ in some hospitals of major cities in Iran. Perineal pain adversely affects different aspects of women, including lactation, child care and daily chore. There are several common metodes used for reducing pain and accelerating the episiotomy healing proces, one of them is cinnamon. The purpose of this study is to knowing the pharmacological effect of cinnamon and the effect on perineal pain and healing of episiotomy incision. The study is literature review, we use relevent article in sistematic electronic database (Proquest, EBSCOHOST, Pubmed, and Google scholar) wich contain of 12 article and journal. Based on the study, cinnamon have anti-inflammatory and analgesic properties. The main compounds in cinnamon are cinnamaldehyde, eugenol, cinnzeylanine, cinzeylanol, arabinoxylan, 2hydroxycinnamaldehyde, and 2-benzoloxycinnamaldehyde. Based on the experiment study including 114 postpartum women, showed that cinnamon can be used for reducing perineal pain and improving healing of episiotomy incision.
\end{abstract}

Keywords : Cinnamon, perineal pain, episiotomy

How to Cite: Wulandari, E. T., Kumalasari, Desi. (2017). Herbal untuk Perawatan Masa Nifas; Penggunaan Kayu Manis Untuk Nyeri Perineum dan Luka Episiotomi. Jurnal Aisyah: Jurnal Ilmu Kesehatan. $2(2), 93-98$. 


\section{Aisyah: Jurnal Ilmu Kesehatan 2 (2) 2017, - 94}

Eka Tri Wulandari, Desi Kumalasari

\section{PENDAHULUAN}

Graham, I. D., Carroli, G., Davies, C., Medves, J. M. (2005) Episiotomi merupakan tindakan Obtetrik yang umum dilakukan pada proses persalinan di dunia. Khani, S., Zare, K. (2012) menyebutkan prevalensi episiotomi pada ibu primipara dilaporkan sebesar 43\% sampai $100 \%$. bahkan di Iran dilaporkan hampir 100\% rumah melakukan tindakan episiotomi.

Francisco A. A., de Oliveira SMJV., de Oliveira Santos J., da Silva FMB. (2011) Rasa sakit pada luka perineum dengan episiotomi bisa empat kali lipat lebih sakit dibanding perineum tanpa luka episiotomi. East, C. E., Sherburn, M., Nagle, C., Said, J., Forster, D. (2012) rasa sakit pada bekas episiotomi dapat mempengaruhi kondisi ibu pada masa nifas, antara lain saat laktasi, perawatan bayinya, dan aktivitas kesehariannya. Masa post-partum merupakan masa-masa yang sangat sensitif bagi ibu, karena pada masa itu ia harus memikirkan proses kesembuhan dirinya dan kebutuhan bayi nya yang baru lahir di saat yang bersamaan. Oleh karena itu proses kesembuhan perineum yang baik dan efektif akan sangat mempengaruhi kondisi ibu dalam menghadapi masa nifas.

East, C. E., Sherburn, M., Nagle, C., Said, J., Forster, D. (2012) ada beberapa metode yang bisa dipakai untuk mengurangi rasa sakit dan mempercepat penyembuhan luka episiotomi. Penggunaan obat-obat non steroid anti inflamasi (NSAID) merupakan obat-obat yang umum dipakai untuk mengurangi rasa sakit dan mempercepat penyembuhan luka episiotomi, walaupun dilaporkan beberapa obat-obat tersebut dapat menimbulkan efek samping seperti tukak lambung (Simon, 2013). Betadine (Yodium) juga biasa digunakan untuk mencegah infeksi dan membantu penyembuhan luka episiotomi, namun berbagai studi menunjukkan bahwa ia tidak memiliki pengaruh yang signifikan terhadap penurunan jumlah mikroorganisme (Zahrani S. H., Amirali
Akbari, S., Valaei, N, 2002). Beberapa studi meneliti tentang pengaruh obat herbal untuk mengobati luka episiotomi, misal nya lavender (Sheikhan, F., Jahdi, F., Khoei, E. M., Shamsalizadeh, N., Sheikhan, M., Haghani, H, 2012), kunyit (Behmanesh, F., Aghamohammadi, A., Zeinalzadeh, M, 2013), minyak zaitun (Vardanjani, S. A. E., Shafai, F. S., Mohebi, P., Deyhimi, M., Delazar, A., Ghojazadeh, M., Malekpour, P, 2010) dan kayu manis (Mohammadi, A., Mohammad Alizadeh Charandabi, S., Mirghafourvand, M., Javadzadeh, Y., Fardiazar, Z., Effati-Daryani, F, 2014). Akan tetapi secara uji klinis efek obat herbal ini belum banyak dilakukan, sehingga perlu dilakukan studi lebih lanjut tentang pengaruh obat herbal tersebut untuk kesembuhan luka episiotomi.

Tujuan penelitian ini adalah untuk mengetahui efek farmakologi dari kandungan senyawa di kayumanis dan manfaatnya untuk perawatan luka episiotomi.

\section{METODE}

Suatu tinjauan literatur (literatur rewiew) terhadap teori-teori yang relevan. Sumber tinjauan meliputi studi pencarian sistematis database (proquest, ebsco, elsheiver, google cendikia) yang berjumlah 12 jurnal.

\section{HASIL DAN PEMBAHASAN}

\section{Efek farmakologi dari kandungan senyawa aktif pada kayumanis}

Kayu manis merupakan salah satu dari sekian banyak rempah herbal yang sudah lama dimanfaatkan oleh masyarakat diseuluruh dunia. Studi secara invivo dan invitro menunjukan bahwa kandungan senyawa aktif dan derivatnya yang terkandung dalam kayumanis mempunyai efek farmakologi, antara lain sebagai antifungal, antikardiovaskular, antikanker, antiinflamasi, antiulser, antidiabetes, antivirus, antihipertensi, antioxidan, dan penurun lemak dan kolesterol (Shen et al, 


\section{Aisyah: Jurnal Ilmu Kesehatan 2 (2) 2017, - 95}

Eka Tri Wulandari, Desi Kumalasari

2012). Beberapa efek terapeutik pada kayumanis dapat dilihat pada tabel 1 . Kandungan senyawa aktif yang terdapat dalam kayumanis antara lain cinnamaldehyde, eugenol, cinnzeylanine, cinzeylanol, arabinoxylan, 2hydroxycinnamaldehide, dan 2benzoloxycinnamaldehyde (Shen et al, 2012)

Pada percobaan dengan tikus laboratorium menunjukan secara signifikan bahwa kayumanis juga dapat digunakan sebagai analgesik dan penyembuh luka (Ranasinghe, P., Jayawardena, R., Galappaththy, P., Constantine, G. R., de Vas Gunawardana, N., Katulanda, P)

Penelitian Mohammadi A, et al tentang efek salep kayumanis $2 \%$ pada nyeri perineum dan proses kesembuhan luka episiotomi menunjukan hasil bahwa Kayu manis dapat digunakan untuk mengurangi nyeri perineum dan mempercepat proses kesembuhan dari luka episiotomi.

Tabel 1. Efek Farmakologis Kayu manis dan senyawanya

\begin{tabular}{|c|c|c|c|}
\hline Efek farmakologis & Spesies tanaman & Bahan/senyawa & Referensi \\
\hline Anti jamur & - & $\begin{array}{l}\text { Cinnamaldehyde } \\
\text { (vapour) }\end{array}$ & Lima, 1993; Quale, 1996; Singh,1995 \\
\hline $\begin{array}{l}\text { Peningkatan } \\
\text { Bronkokonstriksi, } \\
\text { Aritmia }\end{array}$ & C. Philippinense & Cinnamophilin & SU,1999; Yu,1994a; 1994b \\
\hline $\begin{array}{l}\text { Anti Kanker, } \\
\text { Imunomodulator }\end{array}$ & C. Cassia & $\begin{array}{l}\text { Extracts, } \\
\text { cinnamaldehyde }\end{array}$ & $\begin{array}{l}\text { Abraham,1998; Ka,2003; Koh,1998; } \\
\text { Le,1999; Nishida,2003; Schoene, } 2005\end{array}$ \\
\hline Anti Ulkus & $\begin{array}{l}\text { C. Cassia } \\
\text { C. Zeylanicum }\end{array}$ & Water extract & Keller, 1992 \\
\hline Anti Inflamasi & C. Cassia & Water extract & Nagai,1982a,1982b \\
\hline Anti Oksidan & C. Zeylanicum & $\begin{array}{l}\text { Essetial Oil, Water, } \\
\text { and alcoholic extract }\end{array}$ & $\begin{array}{l}\text { Chericoni,2005; Dragland, 2003; } \\
\text { Khan,2003; Kim,2006a; Macini- } \\
\text { Filho,1998; Okawa, 2001; Shobana, } \\
2000\end{array}$ \\
\hline $\begin{array}{l}\text { Kolesterol dan } \\
\text { Penurunan Lipid }\end{array}$ & C. Cassia & Plant & Khan, 2003; Kim, 2006a \\
\hline Anti Diabetes & $\begin{array}{l}\text { C. Cassia } \\
\text { C. Zeylanicum }\end{array}$ & $\begin{array}{l}\text { Plant, water extact, } \\
\text { cinnamaldehyde }\end{array}$ & $\begin{array}{l}\text { Anderson, 2004; Altshuler, 2007; Berno, } \\
\text { 1992; Blevinsi, 2007; Broadhurst, 2000; } \\
\text { Cao, 2007; Chase, 2007; Impart- } \\
\text { Radosevich, 1998; Jarvil-Taylor, 2001; } \\
\text { Kannappan, 2006; Kan, 1990; Kim, } \\
\text { 2006a;2006b, Kreydiyyeh, 2001; Lee, } \\
\text { 2001; Mang, 2006; Onderoglu, 1999; } \\
\text { Pham, 2007; Qin, 2003; 2004; Roffey, } \\
\text { 2006; Shen, 2010; Subash, 2007; } \\
\text { Suppapitipom, 2006; Taher, 2004; } \\
\text { Taplur, 2005; Vanschoonbeek, 2006; } \\
\text { Verspohi, 2005; Wang, } 2007\end{array}$ \\
\hline Anti Virus & C. Cassia & $\begin{array}{l}\text { Extract, } \\
\text { Cinnamaldehyde }\end{array}$ & Hayashi, 2007; Premanathan, 2000 \\
\hline Anti Hypertensi & C. Cassia & Asetic Acid extrak & Chen, 1981, Prevuss, 2006; Zhou, 1995 \\
\hline $\begin{array}{l}\text { Perbaikan depresi } \\
\text { sistem saraf pusat }\end{array}$ & C. Cassia & Water extract & Harada, 1972; Iwasaki, 2008 \\
\hline Gastroprotection & C. Cassia & $\begin{array}{l}\text { Ethanol and } \\
\text { Methylene chloride } \\
\text { extracts }\end{array}$ & Tabak, 1999 \\
\hline
\end{tabular}


Aisyah: Jurnal Ilmu Kesehatan 2 (2) 2017, - 96

Eka Tri Wulandari, Desi Kumalasari

Efek kayumanis untuk nyeri perineum dan proses kesembukan luka episiotomi

Penelitian eksperimen untuk mengetahui efek kayumanis terhadap nyeri dan luka episiotomi pernah dilakukan oleh Mohammadi, A., Mohammad-AlizadehCharandabi, S., Mirghafourvand, M., Javadzadeh, Y., Fardiazar, Z., EffatiDaryani, F. (2014) dengan metode double blind randomized placebo control trial. Jumlah responden pada penelitian ini berjumlah 114 ibu pospartum yang dibagi menjadi 2 group. Intervensi dilakukan 1 jam setelah proses episiotomi selesai dilakukan. Responden mendapatkan perawatan salep kayumanis dan salep plasebo sejumlah $2 \mathrm{ml}$ yang di gunakan setiap 12 jam selama 10 hari. Nyeri perineum diukur dengan menggunakan VAS (Visual Analog Scale) dengan skala 110, sedangkan untuk proses kesembuhan luka episiotomi di ukur dengan REEDA ( Redness, Edema, Ecchymosis, Discharge, Approximation) dengan skala 0-15. Hasil penelitian ini menunjukan skore pada kelompok salep kayumanis secara signifikan lebih rendah dibanding kelompok plasebo, baik untuk nyeri maupun proses kesembuhan luka. 


\section{DAFTAR PUSTAKA}

Behmanesh, F., Aghamohammadi, A., Zeinalzadeh, M. (2013). Khafri Effects of Olive Oil Sitz Bath on Improvement of Perineal Injury After Delivery. Koomesh. 14(3): 309-315.

East, C. E., Sherburn, M., Nagle, C., Said, J., Forster, D. (2012). Perineal Pain Following Childbirth: Prevalence, Effects on Postnatal Recovery and Analgesia Usage. Midwifery. 28(1): 93-97.

Francisco A. A., de Oliveira SMJV., de Oliveira Santos J., da Silva FMB. (2011). Evaluation and Treatment of Perineal Pain Invaginal Postpartum. Acta Paul Enferm.

Graham, I. D., Carroli, G., Davies, C., Medves, J. M. (2005). Episiotomyrates Around the World: an Update. Birth. 3(23): 219-22.

Khani, S., Zare, K. (2012). The frequency of Episiotomy and its Related Factors. Iran J Nurs. 24(74): 45-52. Persian With Abstract in English.

Mohammadi, A., Mohammad-AlizadehCharandabi, S., Mirghafourvand, M., Javadzadeh, Y., Fardiazar, Z., EffatiDaryani, F. (2014). Effects of Cinnamon On Perineal Pain and Healing of Episiotomy: A Randomized Placebo-Controlled Trial. J Integr Med. 2014 May.

Ranasinghe, P., Jayawardena, R., Galappaththy, P., Constantine, G. R., de Vas Gunawardana, N., Katulanda, P. Response to Akilen Efficacy and Safety of 'True' Cinnamon (Cinnamomum zeylanicum) as $\mathrm{A}$
Pharmaceutical Agent In Diabetes: $a$ Systematic Review.

Sheikhan, F., Jahdi, F., Khoei, E. M., Shamsalizadeh, N., Sheikhan, M., Haghani, H. (2012). Episiotomy Pain Relief: Use of Lavender Oil Essence in Primiparous Iranian Women. Complement Ther Clin Pract. 18(1): 66-70.

Shen et al. (2012). Beneficial Effects of Cinnamon on the Metabolic Syndrome, Inflammation, and Pain, and Mechanisms Underlying These Effects - A Review Journal of Traditional and Complementary Medicine 2 (2012).

Simon, L. S. (2013). Nonsteroidal antiinflammatory drugs and theirrisk: a story still in development. Arthritis Res Ther.

Tork Zahrani S. H., Amirali Akbari, S., Valaei, N. (2002). Comparison of The Effect of Betadine And Water In Episiotomy Wound Healing. Feyz $J$ Kashan Univ Med Sci. 5(20): 80-85. Persian With Abstract In English.

Vardanjani, S. A. E., Shafai, F. S., Mohebi, P., Deyhimi, M., Delazar, A., Ghojazadeh, M., Malekpour, P. (2010). Wound Healing Benefits of Curcumin for Perineal Repair After Episiotomy: Results of An Iranian Randomized Controlled Trial. Life Sci J. 9(4). 
Aisyah: Jurnal Ilmu Kesehatan 2 (2) 2017, - 98

Eka Tri Wulandari, Desi Kumalasari 